\title{
The Predictive Effects of Reading Motivation Constructs and Reading Practice on Moroccan Fourth Graders Reading Comprehension Achievement: An Analysis of PIRLS 2011 Study
}

\author{
Nadori Neirouz \\ Chouaib Doukkali University, El-Jaddida
}

\begin{tabular}{|c|c|}
\hline ARTICLE INFO & ABSTRACT \\
\hline $\begin{array}{l}\text { Keywords: } \\
\text { Reading Comprehension } \\
\text { Achievement } \\
\text { PIRLS } 2011 \\
\text { Reading Motivation } \\
\text { Constructs } \\
\text { Reading Practice } \\
\text { Multiple Linear } \\
\text { Regression }\end{array}$ & $\begin{array}{l}\text { More than any other skill, reading proficiency is important to } \\
\text { effectively navigating the school curriculum, shaping each } \\
\text { individual's trajectory through life, and actively taking part in } \\
\text { broader society (Martin, Mullis \& Hooper, 2011). The aim of the } \\
\text { present study is to examine the effects of reading motivation } \\
\text { constructs and independent reading practice on predicting Moroccan } \\
\text { students' reading comprehension development. This study is framed } \\
\text { within virtuous circle of reading model to explain the interaction } \\
\text { between the reading behavior, reading practice and reading } \\
\text { comprehension achievement (Stanovich, 1986, 2009). Data of } 7805 \\
\text { grade } 4 \text { students participating in PIRLS 2011 is analyzed. A } \\
\text { multilevel linear regression analysis is used to model the relationship } \\
\text { between the investigated variables. These individual factors explain } \\
\text { 14\% of variance in reading comprehension achievement. Reading } \\
\text { motivation constructs particularly reading self-efficacy are found to } \\
\text { positively affect reading scores. Further, results indicate that } \\
\text { independent reading practice has the most predictive value among all } \\
\text { the variables investigated in this study. These findings have } \\
\text { important practical implications for the enhancement of reading } \\
\text { skills with that of reading self-efficacy. }\end{array}$ \\
\hline
\end{tabular}

\section{Introduction}

Reading is one of the most important abilities students acquire as they progress through their school years (Kintsch, 2013; Mullis, Martin, Foy, \& Hooper 2017). Analysis directed at examining influences on reading achievement has been the central concern of many largescale international studies such as PISA and PIRLS. These international programs aimed at constructing benchmarks of literacy development for the $21^{\text {st }}$ century and provided rich background data about factors affecting reading achievement.

The PIRLS (Progress in International Reading Literacy Study) was first conducted in 2001 as a follow up of the IEA's 1991 Reading Literacy Study. Conducted every five years, 2001, 2006, 2011, 2016, PIRLS evaluated the reading comprehension development of fourth graders. This year of schooling constitutes a transition point in children's development as readers "have learnt how to read and are now reading to learn" (Martin \& Mullis, 2011.p. 3). Over 60 countries and sub-national were involved in this study; Morocco was one of the participating countries.

PIRLS program provides the opportunity to the participating countries to assess the efficiency of their educational system and monitor progress in reading comprehension achievement across four time points. Indeed, PIRLS makes a rich database to allow first an international comparison of the reading comprehension achievement. Second, it enables decision makers

* Corresponding Author E-Mail Address: Nadori_neirouz@hotmail.com 
to specify objectives for improvement. Finally, it helps identify strengths and weaknesses of educational contexts for learning to read in each country.

The PIRLS database is an extremely useful and rich resource for understanding, exploring, and analyzing factors influencing reading comprehension achievement. PIRLS incorporates relevant background information about the way educational opportunities are available to students as well as the factors that affect the way students make use of these opportunities. The background data provides extended information at two levels; student and school level. The present study is mainly concerned with the investigation of factors at the student level likely to predict variations in students' reading comprehension achievement.

The 2011 PIRLS report revealed the low performance of Moroccan students. They have been ranked last with an average score of 310 points. According to PIRLS benchmarking standard, this average is below the lowest benchmark suggesting lack of minimal reading skills (Ibrouk, 2016). Based on this, the low reading competency of Moroccan students arouses a deep interest in examining factors likely to explain variations in Moroccan students' reading comprehension development. The main focus is on free reading practice frequency and motivational dimensions mainly, reading attitudes, motivation, engagement, and reading selfefficacy. Moreover, there has been a long tradition of reading research investigating the cognitive prerequisites of reading comprehension development on the neglect of motivational determinants. Research examining the unique contribution of reading motivational components to reading comprehension achievement has long been undermined (Retelsdorf et al., 2011; Taboada, Tonks, Wigfield \& Guthrie, 2009). Results should assist in the improvement of independent reading practice amount and frequency with that of reading motivation constructs with the likelihood of increasing reading skills. To address this purpose, the data collected in PIRLS 2011 was analyzed with the purpose of examining the extent to which these motivational construct along with reading practice frequency affect the reading comprehension development of Moroccan fourth graders. Therefore, the current analysis endeavors to answer to main questions:

1) To what extent reading motivation constructs (reading attitudes, motivation, engagement, and reading self-efficacy) and frequency of reading practice predict reading comprehension achievement?

2) How much of reading variation is explained by the combined effects of reading motivation constructs and frequency of reading practice?

To address this issue, we first review a selection of pertinent studies that have emphasized the relationship between reading motivation dimensions, reading practice, and reading comprehension achievement. Afterwards, we discuss the methodological procedure adopted in this study and then present the results obtained. Finally, a discussion of results and recommendations that are meant to improve Moroccan students reading comprehension achievement are provided.

\section{Literature Review}

The importance of motivational factors in predicting achievement has been widely investigated in educational and developmental psychology. Such interest is not only due to the fact that students' motivational aspects are substantial in explaining achievement but because these dimensions are malleable and can be subjected to change as well. PIRLS 2001, 2006, 2011 revealed a strong relationship between students' motivation components and trends in reading comprehension achievement at the international level (Mullis et al., 2017). These motivational determinants are used as a proxy to measure variations in students' 
reading scores. Though a general association is indicated between motivation factors and reading comprehension achievement, the degree of association may vary across countries.

A positive attitude toward reading is probably one of the most substantial attributes of a lifelong reader. Good readers generally exhibit a more positive attitude than do learners who have not had a great deal of success with reading (Mullis, Martin, Kennedy, \& Foy, 2012). Children who have developed positive attitudes towards reading are also more likely to choose reading for recreation. Such reading activities may enhance students' interests and confidences in reading and are likely to determine the choice of effective strategies while approaching a reading activity (Wigfield \& Guthrie, 1997, Wigfield, Gladstone \& Turci, 2016).

Large body of research has suggested a strong relation between reading attitudes and reading comprehension achievement. A case in point is Wigfield and Guthrie's (2000) study. The researchers claimed that the attitudes students hold towards reading at early stages of their schooling play a critical role in subsequent reading achievement. Similarly, Kush and colleagues (2005) reported that students' attitudes measured in grade 2 and 3 predicted reading comprehension achievement in grade 7. Later, Bastug (2014) revealed in a study conducted on $10284^{\text {th }}$ and $5^{\text {th }}$ grade students that reading attitudes and reading comprehension significantly correlate with each other. Corroborating results have been reported elsewhere. In effect, Sutahayu (2017) found that vocabulary mastery, reading comprehension and reading attitudes were strongly related. His finding revealed that reading attitudes make $36.29 \%$ effective contribution to vocabulary mastery and reading comprehension. Reading attitudes were not only found to influence reading comprehension, they were correlated with reading motivation as well (wigfield, Gladstone \& Turci 2016).

In addition to students' reading attitudes, reading motivation is substantial to effectively engage reading tasks (Anmarkrud \& Bråten, 2009; Logan, Medford, \& Hughes, 2011). It is generally agreed that high reading motivation contributes positively to reading achievement as well as the likelihood of effective reading behavior (Morgan \& Fuchs, 2007; wigfield, Gladstone \& Turci, 2016). Students who are motivated to read are likely to master challenging concepts encountered in the text (Griffiths \& Snowling, 2002). Conversely, poor readers usually have little if no interest in engaging reading activities as they lack the motivation to persist in face of setbacks (Wigfield, Gladstone \& Turci, 2016).

Research has also been interested in categorizing motivation. Fitzgibbons (2004) drew the attention to the multi-variant nature of reading motivation. He labeled three motivational concepts: a) learners' interest in reading, b) his or her attitudes towards reading, and c) his or her reading related behavior. But most of the literature divides motivation into two distinct constructs: intrinsic and extrinsic motivation. Intrinsic motivation is the inner impulse. Students who are internally driven to read find it to be interesting and enjoyable (Deci \& Ryan, 1985). Although it is theorized that all human beings are born with intrinsic motivation to learn, contexts such as the home and school can either boost or restrict this inner motivation. On the other hand, extrinsic motivation stands for the external motive such as praise, career success, money, and other incentives that stimulate the reader. Research consistently demonstrates that intrinsic motivation is more closely associated with reading achievement than extrinsic motivation (Becker, McElvany, \& Kortenbruck, 2010; Schiefele, Schaffner, Möller, \& Wigfield, 2012). Schiefele, Schaffner, Moller, and Wigfield (2012) synthesized research of the last 20 years with reference to motivation and related reading behavior. They concluded a strong relationship between reading motivation and reading behavior (amount, strategies, and preferences) and reading competence (reading skills and comprehension). Research on reading motivation among Moroccan students using large database is scarce, to the best of our knowledge, and so it, too has become a major concern of the present research. 
Research has consistently demonstrated that being engaged in reading activities generally lead to high reading achievement scores. In a study conducted by Ivey and Johnston (2013) on the relationships between students perceptions of achievement and processes of engaged reading in the classrooms highlighted the reciprocal influence of engaged reading on one students' development of reading skills. Other study reports did not only claimed the direct effect of engagement on reading outcomes but also emphasized the mediating role it plays between motivational components and achievement. Accordingly, Guthrie, and Klauda (2013) reported that reading motivation was associated directly and indirectly with reading comprehension achievement through engagement. They added that advanced readers displayed high motivation and engagement than did struggling readers. Guthrie and klanda (2015) further claimed that reading engagement meditated the association between selfefficacy and reading achievement. In the same vein, Galla et al (2014) conducted a longitudinal study to examine the within-person and between-person effect of effortful engagement, self-efficacy and reading performance. Findings revealed that within-person change in effort engagement and self-efficacy scores significantly predicted concomitant and within person change in reading test score and that effortful engagement mediated the relation between Self-efficacy and reading growth.

Self-efficacy perception has been deeply rooted in the literature and hypothesized to have a strong impact on other self-beliefs, self-regulation, and achievement (Pajares, 1996; Zimmerman \& Bandura, 1994). Self-efficacy refers to how confident a person feels in organizing and implementing behaviors in situation that may contain novel, unpredictable and possibly stressful elements (Bandura, 1997). If students believe that reading tasks are beyond the scope of what can be achieved successfully, they will have tendency to adopt avoidance behaviors and give up in face of setbacks. In contrast, if students hold high selfefficacy perceptions, they will persist in order to successfully complete the reading activity. Accordingly, Wigfield and Guthrie (1997) carried out a study on a sample of 105 students in grade 4 and 5. Findings evidenced that reading self-efficacy was correlated with reading amount and reading breadth. Similar results have been reported by Smith et al., (2012). Their findings accord with those of Wigfield and Guthrie's in that reading self-efficacy beliefs were strong determinants of students' reading comprehension development.

Possessing a high sense of self-efficacy as a reader can influence effort expenditure and task persistence. High self-efficacious students exhibit potent efforts and persist longer and therefore, feel more confident to engage in challenging reading activities (Galla et al. 2014). Conversely, low self-efficacious students doubt their abilities to perform specific tasks, slacken their efforts, and avoid task accomplishment (Bandura \& Schunk, 1981). Reading self-efficacy includes two perceptions. The first is general reading self-efficacy or the degree of confidence one exhibits while engaging a reading activity. The second is task specific and stands for the ability to successfully perform specific reading tasks or strategies such as making inferences, making predictions and/or evaluating the text. To be consistent with PIRLS assessment framework, the present study is concerned with measuring the effect of general reading self-efficacy on reading comprehension achievement.

From the perspective of educational pedagogy, the issue regarding the amount of time spent on reading is a prerequisite for reading comprehension skill development (Samuels \& Wu, 2004; Mol \& Bus, 2011). Samuels and Wu (2004) conducted an experimental study to investigate how the amount of time spent on independent reading affected reading comprehension achievement. The results revealed that the time spent reading had a strong impact on reading comprehension skill enhncement. The experiment also indicated that lessskilled readers demonstrated significantly greater gains in word recognition and vocabulary than good readers who evidenced better gains on comprehension. Other studies were also concerned with the investigation of the effect of reading practice on reading comprehension 
achievement. Stanovich, West, Cunnigham, Cipielewski, and Siddiqui's (1996) study was a case in point. The researchers posited the eventual effect of reading practice time on reading comprehension skill development. While these researchers put forward the direct effect of the amount of reading practice on reading comprehension achievement, others posited that reading motivation constructs regulated levels of print exposure which in turn lead to better reading comprehension skills (Retelsdorf, Koller, \& Moller, 2014). Indeed, reading motivation researchers often draw on the idea that high levels of reading motivation and reading self-efficacy beget higher amounts of reading practice (e.g., Morgan \& Fuchs, 2007; Schiefele et al., 2012). Students endowed with higher levels of reading self-efficacy are assumed to engage in more frequent and effective reading practice compared to their counterparts who displayed lower levels of reading self-perceptions (Morgan \& fuch, 2007; Stanovich \& Cunnigham 1986; Wigfield \& Guthrie, 1997).

\subsection{Theoretical Framework}

This study is formulated within the Matthew effect framework developed by Stanovich (1986, 2009). The researcher applied this framework to reading development and described it as a developmental process in that initial advantage in reading outcomes engenders further advantage and vice-versa. Stanovich transformed this concept into a model called the virtuous circle of reading. This model emphasizes the potential that that increased differences in reading achievement are mainly due to self-reinforcing reciprocal causal mechanisms that connect reading behavior to internal and environmental factors. Within this framework, the role of reading practice and behavior is stressed (Stanovich, 1986, 2000). The virtuous circle of reading focuses on the notion that proficient readers display more motivation to read and engage in increased reading practice. However, less skilled readers are less motivated to read and demonstrate low levels of print exposure. The reciprocality of this model lies in the fact that improved exposure to print fosters the development of vocabulary and reading gains. As the latter improve, reading motivation, engagement, and confidence increase further. Conversely, lack of exposure and practice on the part of less-skilled readers delays the development of reading abilities and therefore the meaning is restrained, unrewarding reading experiences are heighten, and reading practice is refrained or merely performed without real cognitive development (Pfost, Hattie, Dofler \& Artelt, 2014).

When investigating the development of reading comprehension, considerable body of research has adopted this framework in their analysis. It was found that the reciprocal cumulative process involving the reading practice and the personal assets of learners were responsible for the improvement or regression of reading gains (Harlaar et al., 2007). Additionally, strong relationships were found in observational studies (McElvany, Kortenbruck, \& Becker, 2008; Morgan \& Fuchs, 2007). Morgan \& Fuchs (2007) posited a strong causal interaction between reading achievement, reading behavior, and reading practice creating in the long run a relationship between initial reading level and successive reading comprehension development. In another méta-analytical study presented by Mol \& Bus (2011), print exposure and the development of reading components highly correlated. The more exposure to print materials students demonstrated the more proficient in comprehension and technical reading and spelling they became and vice versa.

\section{Method}

The present analysis was carried out using the raw, restricted-access 2011 PIRLS data. It offered the opportunity to examine the relationship between reading behavior, reading practice, and reading comprehension achievement. The reading behavior was built upon the following reading motivational constructs: reading attitudes, reading motivation, reading engagement and reading self-efficacy. The reading practice was addressed based on students' 
degree of exposure to print materials outside school while the reading achievement was measured through a reading comprehension achievement test. To that end, the study followed a correlational research design to investigate the hypothesized association between these variables. It is assumed that the selected variables might explain variations in reading achievement and that they are malleable factors and amenable to policy interventions.

\subsection{Sample}

The sample was derived from PIRLS 2011 Morocco study. PIRLS adopted two level stratified random sampling design with schools selected at the first stage and intact classes at the second stage. Over a population of 602,798 students and 17,390 schools, PIRLS 2011 recruited a number of 284 public and private schools and 7,805 students based on several coverage and exclusion criteria. The school level exclusion criteria selected were as follow: 1- schools which were inaccessible due to their geographically remote location, 2- schools that were very small in size and include fewer students in the target grade, and 3- schools offering a grade structure or curriculum radically different from mainstream educational system. At the student level exclusion, students with functional or intellectual disabilities as well as students who were unable to read or speak the language of the test weren't involved in the study.

\subsection{Instruments}

The reading comprehension test was designed to assess the fourth graders' reading comprehension achievement. The test combined 10 passages and questions covering a wide range of text types on classroom experiences. Purposes for reading and processes of comprehension constituted the basics framework for the PIRLS written assessment of reading comprehension. The PIRLS assessment covered two inclusive purposes for reading that related to most of the reading done by young students both in and out of school: 1- reading for literary experience and 2- reading to acquire and use information. Four types of comprehension processes were measured namely, focusing on and retrieving explicitly stated information, making straightforward inferences, interpreting and integrating ideas and information, and examining and evaluating content, language, and textual elements. These reading comprehension processes tapped on both cognitive and metacognitive reading comprehension strategies.

The PIRLS 2011 utilized questionnaire surveys to gather extensive information about the teaching and learning environment based on students, teachers and school principals' reports. The present study confined itself to the students' questionnaires addressing aspects of reading motivation and reading practice outside school. Particularly, the student's questionnaires incorporated questions on students' reading attitudes, reading motivation, reading engagement, and reading self-efficacy as well as frequency of reading that students had engaged in outside school. The motivational variables were calculated according to students' level of agreement with the statements each of which had four point scales: "agree a lot", "agree a little", "disagree a little", and "disagree a lot". On the other hand, the reading practice was measured based on frequency of the reading performed outside of school. The variables or predictors under investigation were created by summing students' responses to the component items.

\subsection{Procedure}

The study utilized descriptive and inferential statistics to organize and analyze the quantitative data. With regard to the descriptive statistics, we computed the minimum, maximum, mean, and standard deviation. The inferential statistics employed was the multiple linear regression analysis. This statistical method served to predict how much the reading 
scores are expected to increase or decrease for every one unit increase or decrease in the reading behavior and reading practice variables. To resolve the problem of missing values that is frequent in large scale studies such PIRLS, a listwise mode is utilized. The listwise mode allows for the use of only cases with complete data. It is important to mention that the use of listwise method instead of mean substitution is due to the fact that mean substitution technique is used in cases measuring only continuous variables. Since the present study incorporates both continuous and categorical variables, the listwise mode is more applicable to deal with the problem of missing values. It is also noteworthy that the dependent variable (reading comprehension achievement) is used as a plausible value variable.

\section{Results}

This study is undertaken to gain a better understanding about which reading motivation constructs are more effective in promoting reading comprehension achievement. Additionally, this study tested the extent to which independent reading practice frequency predict/explain reading comprehension scores. Before revealing the results of this analysis, it is necessary to examine how Moroccan fourth graders achieved in PIRLS reading assessment.

\subsection{Morocco reading achievement results in PIRLS}

Moroccan students scored 310 points and were ranked last among all the participating countries. This score is below the low benchmark. Researchers agreed that students who achieved below 400 have no reading skills and are on the edge of illiteracy (Ibrouk, 2016). According to PIRLS reading assessment framework, students at this range have demonstrated very low proficiency in focusing on and retrieving explicitly stated information and no proficiency in a) making straight forward inferences, b) interpreting and integrating ideas and information, and c) examining and evaluating content, language, and textual elements (PIRLS, 2011). Even worse, the percentage of students within this scale is very high. The following figure (figure 1) describes the distribution of Moroccan students in the five benchmarking categories.

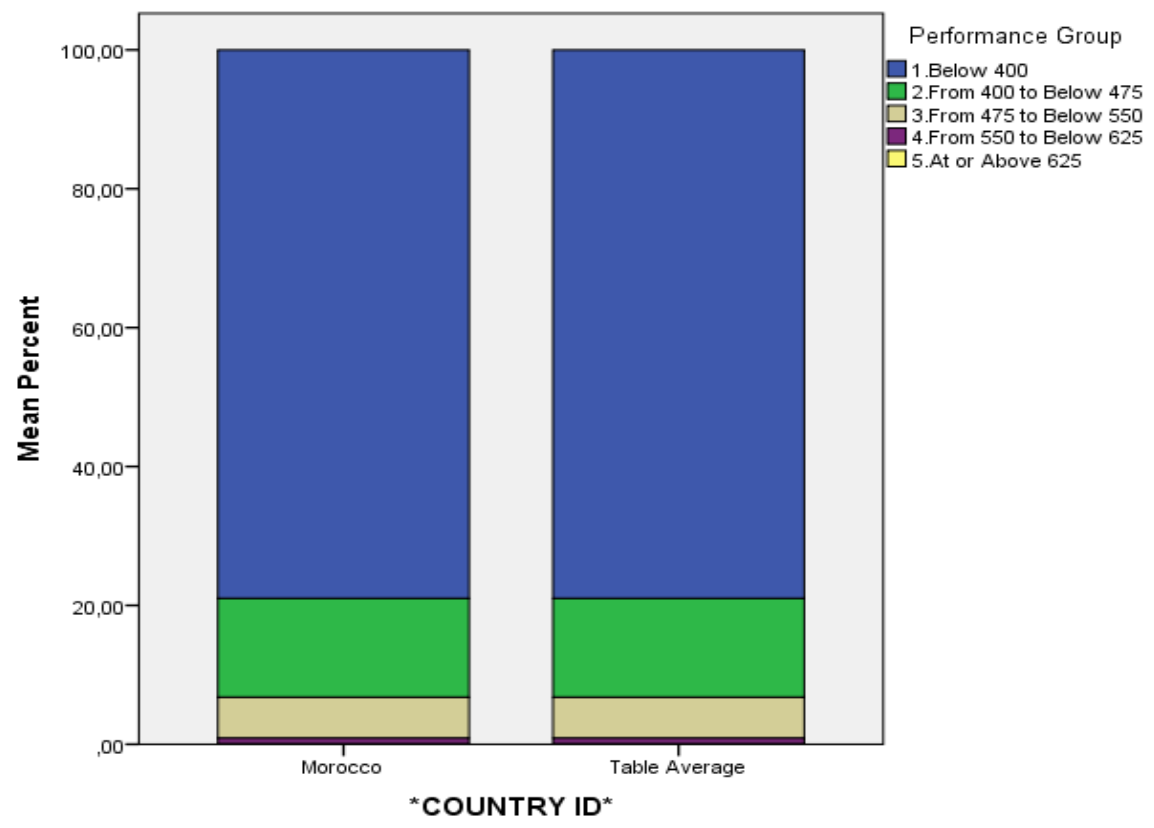

figure 1. Distribution of Moroccan students reading scores in the five benchmarking categories 
By analyzing the distribution of the reading scores in PIRLS 2011, results evidence that 79\% of Moroccan students scored below the low level benchmark with a standard error 1.27. This reveals that 4 out of 5 students are in the verge of illiteracy. These readers lack basic reading skills. On the other hand, the percentage of higher achievers is significantly low. Only 3 out of 7.798 students attained the advanced benchmark with a standard error .04 . Those students demonstrated a good competency in retrieving relevant information, providing adequate inferences, and interpreting and evaluating content of the text.

The Moroccan students' results in PIRLS 2011 assessment are the accumulation of many years of underachievement since PIRLS 2001. In fact, Moroccan students' achievement dropped 40 points from 350 points in 2001 to 310 points in 2011. Morocco's average rating has not progressed. Yet, it has known the most significant decline among all participating countries. Table (1) below describes the reading trends of Moroccan students at PIRLS 2001, 2006, and 2011.

Table 1.

Trends in reading comprehension achievement

\begin{tabular}{ccc}
\hline Year & Read. Achievement & Standard Error \\
\hline 2011 & 310 & $(3.9)$ \\
2006 & 323 & $(5.9)$ \\
2001 & 350 & $(9.6)$ \\
\hline
\end{tabular}

The reading results of Moroccan fourth graders in the three assessment points raise questions about the quality of the educational system in Morocco and the factors likely to explain variation in their reading achievement. The present analysis confines itself to the investigation of factors at the students' level namely, motivational constructs and students reading practice outside school and the extent to which they may contribute to the development of reading comprehension. Following are the results of the descriptive statistics of the variables under investigation (table 2).

Table 2.

Mean of motivational constructs and reading practice

\begin{tabular}{llccccc}
\hline & $\mathrm{N}$ & Minimum & Maximum & Mean & Std. Dev \\
\hline \multirow{2}{*}{ Morocco } & Reading practice & 625341 & 1 & 4 & 2,01 & 1,12 \\
& Reading engagement & 618033 & 2,07 & 14,32 & 10,77 & 2,20 \\
& Reading self-efficacy & 609123 & 1,97 & 14,35 & 9,10 & 1,57 \\
& Reading attitudes & 622516 & 2,54 & 14,95 & 9,89 & 1,67 \\
& Reading motivation & 606567 & 2,45 & 12,36 & 10,34 & 2,14 \\
& Reading comprehension & 625341 & 5,26 & 639 & 317 & 102 \\
achievement & 598925 & & & & \\
& Valid N (listwise) & & & & & \\
\hline
\end{tabular}

The mean score of independent reading frequency is 2.01, suggesting that Moroccan fourth graders practice reading once or twice a week. The value range for reading practice frequency is 1 to 4 times. Regarding the reading motivational constructs, students' reading engagement mean score is 10.77, revealing that fourth graders are engaged in reading lessons at school. The value range for students' engagement is 7.9 (not engaged) and 10.6 (engaged). Additionally, the descriptive results revealed that the mean score of students' motivation to read is 10.34 (which is less than 10.6), indicating that students are somewhat motivated to read. The value range for students' motivation to read is 7.6 (not motivated) and 10.6 (motivated). The mean score for students' reading attitudes is 9.89 , suggesting that students somewhat like reading. The range value for students' attitudes towards reading is 7.6 (don't like reading) and 10.6 (like reading). Finally, the mean score for students' confidence in 
reading is 9.10 which suggests that students are labeled somewhat confident in successfully performing reading task with a value range of 7.9 (not confident) and 10.6 (confident).

\subsection{The predictive effect of motivational constructs and reading practice}

The first research question examined the extent to which reading motivation constructs and reading practice frequency predicted/explained Moroccan fourth graders reading comprehension achievement. This research question was addressed using multiple linear regression coefficient. The results are displayed in table 3.

Table 3.

The effect of reading motivational constructs and reading practice frequency on reading development

\begin{tabular}{|c|c|c|c|c|c|c|c|}
\hline Idcntry & Variable & $\begin{array}{l}\text { Regression } \\
\text { Coefficient }\end{array}$ & $\begin{array}{c}\text { Regression } \\
\text { Coefficient } \\
\text { (s.e.) }\end{array}$ & $\begin{array}{c}\text { Regression } \\
\text { Coefficient } \\
\text { (t-value })\end{array}$ & $\begin{array}{l}\text { Stndrdzd. } \\
\text { Coefficient }\end{array}$ & $\begin{array}{l}\text { Stndrdzd. } \\
\text { Coefficient } \\
\text { (s.e.) }\end{array}$ & $\begin{array}{l}\text { Stndrdzd. } \\
\text { Coefficient } \\
\text { (t-value) }\end{array}$ \\
\hline \multirow{6}{*}{ Morocco } & (CONSTANT) & 32,44 & 22,66 & 1,43 & * & • & . \\
\hline & Read.Engagement & 3.58 & 1.93 & 1.85 & .08 & .04 & 1.85 \\
\hline & Read. Self-efficacy & 12.44 & 2.08 & 5.97 & .19 & .03 & 6.76 \\
\hline & Read.Attitude & 8.54 & 1.94 & 4.39 & .14 & .03 & 4.49 \\
\hline & Read.Motivation & 4.29 & 1.58 & 2.71 & .09 & .03 & 2.78 \\
\hline & Read. Practice & 16.68 & 4.31 & 3.87 & .07 & .02 & 3.85 \\
\hline
\end{tabular}

No statistically significant linear dependence of the mean of reading engagement on reading comprehension achievement was detected. The t-value of reading engagement was 1.85 which is smaller than the t-value 1.96 (using a standard normal distribution to determine the critical value for the t-statistics), suggesting no statistically significant relation between the two variables. All the remaining motivational constructs namely, reading self-efficacy, reading attitudes and motivation were statistically significant and positive predictors of students' reading comprehension achievement. The regression results also suggested that among the three statistically significant predictors and after controlling for all the other variables, reading self-efficacy had the greatest positive effect on students' reading comprehension achievement with a regression coefficient of (12.44) followed by reading attitudes (8.54) and reading motivation (4.29).

Another pattern of result emerged from this analysis. The reading practice was found to be positive and statistically significant with a coefficient of 16.68 and t-value of 3.87. It is important to mention that this variable indicated the highest coefficient value among all the variables analyzed in this model slightly outstripping reading self-efficacy (12.44). This result suggested that the more frequent the students practice reading outside school, the higher reading comprehension score they attain. Using more technical terms, with every one unit increase in reading practice variable, the reading comprehension scores will tend to increase by 16.68 points. The same principle is applicable to the remaining reading motivational constructs.

\subsection{The combined effects of reading motivation constructs and frequency of reading practice}

The second research question addressed the level of variation in reading scores that can be explained by the joint effects of reading motivation constructs and frequency of reading practice outside of school. Results are displayed in the table 4.

Table 4.

Combined effect of reading motivational constructs and reading practice on reading development

\begin{tabular}{lcccc}
\hline IDCNTRY & R-Square & $\begin{array}{c}\text { R-Square } \\
\text { (s.e.) }\end{array}$ & $\begin{array}{c}\text { Adjusted } \\
\text { R-Square }\end{array}$ & $\begin{array}{c}\text { Adjusted } \\
\text { R-Square } \\
\text { (s.e.) }\end{array}$ \\
\hline Morocco &, 14 &, 02 &, 14 &, 02 \\
Table, Average &, 14 &, 02 &, 14 &, 02 \\
\hline
\end{tabular}


As shown in table (5), the R-square and Adjusted R-square was .14, suggesting that the combined effects of reading motivation dimensions and frequency of reading practice explained $14 \%$ of the variance in reading comprehension achievement of Moroccan students participating in PIRLS 2011 reading assessment.

\section{Discussion}

The current study investigated which dimensions of reading motivation are more likely to be associated with reading comprehension achievement and the extent to which reading practice affects reading comprehension gains. Interpretation of key results and implications for practice will be provided followed by a discussion of future research directions stemming from these results.

Overall, this study revealed that reading motivational constructs and frequency of reading practice contributed to a great extent to the development of reading comprehension of Moroccan fourth graders, except for the reading engagement which was found to be statistically nonsignificant. Among all the reading motivation constructs, reading selfefficacy was found to have the largest effect on reading comprehension achievement. Similar results have been reported elsewhere. Wigfield and Guthrie (1997) found that reading selfefficacy was strongly correlated with reading amount and reading breadth. This pattern of result is also consistent with Lee and Reid's (2016) study. The researchers suggested a strong association between reading self-efficacy and reading achievement. They claimed that low self-efficacious readers stayed away from thought-demanding reading activities and had tendency to withdraw from tasks they perceive as too difficult. However, students with high perceived reading abilities deployed more higher-order reading comprehension strategies which promoted efficient text processing.

The regression coefficient results also conveyed the potential of independent reading in the development of reading outcomes. This confirms previous research findings in that a strong correlation between the amount of independent reading practice and students' reading gains was elucidated in an analysis carried out by Taylor, Frye, and Maruyuma (1990). In the same vein, Samuels and Wu (2004) advanced that the amount of time spent on reading had a significant impact on word recognition, vocabulary, and reading comprehension gains. Results obtained by the current analysis and the widely acknowledged research regarding the powerful effect of reading practice is probably due to its positive influence on reading confidence, attitudes, and motivation. Put differently, children who are exposed to print materials at an early age are likely to have positive early reading experiences generating therefore high levels of reading self-efficacy beliefs, improved reading motivation, and enhanced reading competence (Moll \& Bus, 2011). The other way around, increased reading proficiency may motivate students to engage in independent reading more frequently, sustain positive attitudes towards reading and therefore reinforce their reading self-efficacy perceptions.

The findings of this study are also theoretically supported. The positive relationship between reading behavior (as captured by reading confidence, attitudes and motivation), reading practice (as measured by the amount of time spent in independent reading), and reading comprehension achievement corroborate Stanovich virtuous circle of reading $(1986,2009)$. Stanovich model relates reading development to internal and environmental factors and emphasizes the reciprocal mechanism of these processes. The lack of exposure and practice on the behalf of unskilled readers delays the development of reading abilities and lower their motivation to be involved in effective reading experiences (Cunningham \& Stanovich 1998). On the other hand, high exposure to print materials at an early age develops learners' reading skills and comprehension which increases their self-perceptions about reading and hence enhances subsequent reading experiences. 


\section{Conclusion and Implications}

All in all, findings are consistent with spiral causality of reciprocal mechanism which suggests that print exposure along with reading practice are considered to be driven forces shaping reading comprehension. Indeed, our results provide strong support for the substantial roles the reading practice as well as dimensions of reading motivation play in fostering reading comprehension skills among Moroccan fourth graders. Reading practice frequency and reading self-efficacy were found to have the most powerful influence on reading comprehension achievement. Taking into account the differential effects these factors exert on the learners' reading comprehension development and future academic attainment, important practical implications for intervention efforts are highly required.

Our findings, coupled with others, point to the need to ensure that students in the primary grades move on to subsequent grades with the requisite reading skills. The reading expertise emerges partially when reading motivational aspects are deliberately nurtured. Teachers should be aware that these constructs are malleable and therefore direct reading instructional strategies to promoting reading proficiency and increasing reading motivational dimensions mainly, reading self-efficacy.

Attaining reading excellence is a shared responsibility in which parents should take part. Parents' involvement in their children's education process begins at early developmental stages. Parents should strive to the enhancement of early positive reading-related experiences and environments. Early exposure to print materials might help children develop a set of emotional and cognitive reading skills that would enable them to approach reading activities with more confidence and exhibit more interest in reading materials. Additionally, parents are required to share reading experience with their children and engage in frequent and purposeful discussions about what they read. The length and frequency of such discussions will not only develop children's high-order thinking skills, they may also increase their reading confidence and therefore contribute to recurrent exposure to reading materials.

This study has also important implications to policy makers. Quality primary reading programs are highly recommended to incorporate prerequisite reading skills with that of reading motivation constructs in early grades. Since reading difficulties may follow learners throughout their schooling (Reteldorf, Koller, \& Moller 2014) and sometimes unlikely to be learnt at all (Moll \& Bus, 2011), it is required to design appropriate reading syllabus. An efficient reading program should incorporate strategies targeted to upgrading non-linguistic reading-related aspects held to be beneficial not only to learning of reading skills but also to future educational gains. One program which incorporates strategies for promoting students' reading skills and reading motivation is CORI (concept-oriented reading instruction, e.g., Guthrie et al., 2004). Within CORI, broad dimensions of reading motivation are dealt with and seem to be functionally improved along with reading skills (Guthrie et al., 2007). By that means, one dimension of reading motivation that has been emphasized in this program is reading self-efficacy (Guthrie et al., 2007). Such interventions might not only benefit students to become proficient and confident readers but also spruce up teachers' efficacy and raise their awareness to the straightforward implications motivational constructs have on learners' actual and future reading skill development.

PIRLS study as well as other international studies investigating the Moroccan educational settings provide a rich opportunity to policy makers to identify strengths and weaknesses of the educational context and to specify objectives for improvement. It is also prerequisite to make the data of research conducted at the national level available to researchers in the field to come up with findings likely to overhaul various aspects of the Moroccan education system in general and boosts students learning in particular. 


\section{References}

Anmarkrud, Ø., \& Bråten, I. (2009). Motivation for reading comprehension. Learning and Individual Differences, 19(2), 252-256.

Bandura, A. (1997). Editorial. American Journal of Health Promotion, 12(1), 8-10.

Bastug, M. (2014). The structural relationship of reading attitude, reading comprehension and academic achievement. International Journal of Social Sciences and Education, 4(4), 931946

Csikszentmihalyi, M. (1990). Literacy and intrinsic motivation. Daedalus, 115-140.

Cunningham, A. E., \& Stanovich, K. E. (1998). What reading does for the mind. American educator, 22, 8-17.

Cunningham, A. E., Stanovich, K. E., \& West, R. F. (2014). Literacy environment and the development of children's cognitive skills. Literacy acquisition and social context, 70-91.

Galla, B. M., Wood, J. J., Tsukayama, E., Har, K., Chiu, A. W., \& Langer, D. A. (2014). A longitudinal multilevel model analysis of the within-person and between-person effect of effortful engagement and academic self-efficacy on academic performance. Journal of School Psychology, 52(3), 295-308.

Griffiths, Y. M., \& Snowling, M. J. (2002). Predictors of exception word and nonword reading in dyslexic children: The severity hypothesis. Journal of Educational Psychology, 94(1), 34.

Guthrie, J. T., Klauda, S. L., \& Ho, A. N. (2013). Modeling the relationships among reading instruction, motivation, engagement, and achievement for adolescents. Reading Research Quarterly, 48(1), 9-26.

Guthrie, J. T., McRae, A., \& Klauda, S. L. (2007). Contributions of concept-oriented reading instruction to knowledge about interventions for motivations in reading. Educational Psychologist, 42(4), 237-250.

Guthrie, J. T., Wigfield, A., Metsala, J. L., \& Cox, K. E. (1999). Motivational and cognitive predictors of text comprehension and reading amount. Scientific studies of reading, 3(3), 231-256.

Harlaar, N., Dale, P. S., \& Plomin, R. (2007). From learning to read to reading to learn: Substantial and stable genetic influence. Child Development, 78(1), 116-131.

Ibourk, A. (2016). Performances en lecture au Maroc: approche par genre (No. 1608). OCP Policy Center.

Ivey, G., \& Johnston, P. H. (2013). Engagement with young adult literature: Outcomes and processes. Reading Research Quarterly, 48(3), 255-275.

Jay, S., \& Wu, S. Y. C. (2004). How the amount of time spent on independent reading affects reading achievement: A response to the National Reading Panel.

Kintsch, W. (2013). Meaning in context. In Handbook of latent semantic analysis (pp. 101118). Psychology Press.

Klauda, S. L., \& Guthrie, J. T. (2015). Comparing relations of motivation, engagement, and achievement among struggling and advanced adolescent readers. Reading and writing, 28(2), 239-269. 
Logan, S., Medford, E., \& Hughes, N. (2011). The importance of intrinsic motivation for high and low ability readers' reading comprehension performance. Learning and Individual Differences, 21(1), 124-128.

Martin, M. O., \& Mullis, I. V. (2013). TIMSS and PIRLS 2011: Relationships among Reading, Mathematics, and Science Achievement at the Fourth Grade--Implications for Early Learning. International Association for the Evaluation of Educational Achievement. Herengracht 487, Amsterdam, 1017 BT, The Netherlands.

McKenna, M. C., Conradi, K., Lawrence, C., Jang, B. G., \& Meyer, J. P. (2012). Reading attitudes of middle school students: Results of a US survey. Reading Research Quarterly, 47(3), 283-306.

Mullis, I. V., Martin, M. O., Foy, P., \& Hooper, M. (2017). ePIRLS 2016: International Result in Online Informational Reading. International Association for the Evaluation of Educational Achievement. Herengracht 487, Amsterdam, 1017 BT, The Netherlands.

Nelson, J. M., \& Manset-Williamson, G. (2006). The impact of explicit, self-regulatory reading comprehension strategy instruction on the reading-specific self-efficacy, attributions, and affect of students with reading disabilities. Learning Disability Quarterly, 29(3), 213-230.

Pajares, F. (1996). Self-efficacy beliefs in academic settings. Review of educational research, 66(4), 543-578.

Retelsdorf, J., Köller, O., \& Möller, J. (2011). On the effects of motivation on reading performance growth in secondary school. Learning and Instruction, 21(4), 550-559.

Retelsdorf, J., Köller, O., \& Möller, J. (2014). Reading achievement and reading selfconcept- Testing the reciprocal effects model. Learning and Instruction, 29, 21-30

Ryan, R. M., Connell, J. P., \& Deci, E. L. (1985). A motivational analysis of selfdetermination and self-regulation in education. Research on motivation in education: The classroom milieu, 2, 13-51.

Schaffner, E., Schiefele, U., \& Ulferts, H. (2013). Reading amount as a mediator of the effects of intrinsic and extrinsic reading motivation on reading comprehension. Reading Research Quarterly, 48(4), 369-385.

Schiefele, U., Schaffner, E., Möller, J., \& Wigfield, A. (2012). Dimensions of reading motivation and their relation to reading behavior and competence. Reading Research Quarterly, 47(4), 427-463.

Smith, J. K., Smith, L. F., Gilmore, A., \& Jameson, M. (2012). Students' self-perception of reading ability, enjoyment of reading and reading achievement. Learning and individual differences, 22(2), 202-206.

Stanovich, K E., West, R. F, Cunningham, A. E., Cipielewski, J. and Siddiqui, S. 1996. "The role of inadequate print exposure as a determinant of reading comprehension problems". In Reading comprehension difficulties: Processes and intervention, Edited by: Cornoldi, E. and Oakhill, J. 15-32. Mahwah, NJ: Erlbaum.

Stanovich, K. E. (2009). Matthew effects in reading: Some consequences of individual differences in the acquisition of literacy. Journal of education, 189(1-2), 23-55.

Stutz, F., Schaffner, E., \& Schiefele, U. (2016). Relations among reading motivation, reading amount, and reading comprehension in the early elementary grades. Learning and Individual Differences, 45, 101-113. 
Sutahayu, A. (2017). Correlation between Vocabulary Mastery, Reading Attitudes, and Reading Comprehension of the Second Semester Students of English Education Department of Teacher Training and Education Faculty of Sebelas Maret University in the Academic Year of 2016/2017 (Doctoral dissertation, Universitas Sebelas Maret).

Taboada, A., Tonks, S. M., Wigfield, A., \& Guthrie, J. T. (2009). Effects of motivational and cognitive variables on reading comprehension. Reading and Writing, 22(1), 85.

Taylor, B. M., Frye, B. J., \& Maruyama, G. M. (1990). Time spent reading and reading growth. American Educational Research Journal, 27(2), 351-362.

Wigfield, A., \& Guthrie, J. T. (1997). Relations of children's motivation for reading to the amount and breadth or their reading. Journal of educational psychology, 89(3), 420.

Wigfield, A., \& Guthrie, J. T. (2000). Engagement and motivation in reading. Handbook of reading research, $3,403-422$.

Wigfield, A., Gladstone, J. R., \& Turci, L. (2016). Beyond cognition: Reading motivation and reading comprehension. Child development perspectives, 10(3), 190-195.

Wigfield, A., Guthrie, J. T., Perencevich, K. C., Taboada, A., Klauda, S. L., McRae, A., \& Barbosa, P. (2008). Role of reading engagement in mediating effects of reading comprehension instruction on reading outcomes. Psychology in the Schools, 45(5), 432445.

Zimmerman, B. J., \& Bandura, A. (1994). Impact of self-regulatory influences on writing course attainment. American Educational Research Journal, 31(4), 845-862. 